\title{
An Empirical Study on Alleviating Career English Writing Anxiety through Cooperative Learning in a Chinese Polytechnic Institute
}

\author{
Dongmei Jiang ${ }^{1}$ \\ ${ }^{1}$ Department of Foreign Languages, Shunde Polytechnic, Foshan Guangdong, China \\ Correspondence: Dongmei Jiang, Foreign Languages Department, Shunde Polytechnic Institute, Shunde District, \\ Foshan City, Guangdong Province, China \\ Received: October 9, 2015 \\ Accepted: October 29, 2015 \\ Online Published: December 21, 2015 \\ doi:10.5430/ijhe.v5n1p173 \\ URL: http://dx.doi.org/10.5430/ijhe.v5n1p173
}

\begin{abstract}
This study investigated the effect of cooperative learning on writing anxiety alleviation through a pre-test/post-test assessment. 120 EFL learners from a Chinese polytechnic institute were assigned into two groups: one experimental (cooperative writing) and the other comparison (solitary writing). Results revealed that cooperative learning facilitated mutual assistance among group members, received wide welcome from learners at different levels, reduced their foreign language writing anxiety and increased their writing competence greatly. Interviews were also carried out to probe further how cooperative learning helped to improve learners' psychological health and increase their participation in the writing class. The results are discussed in light of Social Interdependence Theory, relative research on writing anxiety and cooperative learning together with certain local elements. Suggestions are made on how to strengthen group cooperation and increase the effectiveness and efficiency of cooperative learning.
\end{abstract}

Keywords: Writing anxiety, Cooperative learning, Career English writing

\section{Introduction}

Language learning anxiety is a particular combination of the learners' conception about their learning, the teacher and even themselves due to the specific characteristics of learning a new language (Horwitz, 1986, p. 128). As a distinct domain of anxiety, foreign language writing anxiety arises from written communication. Recent studies on writing anxiety tend to indicate its debilitative function on learners' emotion and writing achievement. Cooperative learning (CL), on the other hand, is a teaching theory born in America around the 1970s. Heterogeneous groups are formed in cooperative learning and members of a group work together to complete certain assignments mainly through discussions, while assessment is based on the achievement of the whole group instead of individual work (Johnson \& Johnson, 1999). The unique affective advantages of CL in easing learners' anxiety have been widely accepted (for example Wyeld, 2013; Davidson \& Major, 2014), but CL used in foreign language learning, especially its effect on writing anxiety has got little attention. To provide more evidence in this area, this research implemented CL in a career English writing class in a Chinese polytechnic institute, aiming particularly to explore the affective advantages of cooperative writing compared with traditional individual writing and testify its effectiveness of alleviating students' writing anxiety and improving their writing achievement.

Prior research in language learning anxiety mainly focused on the relationship between anxiety and learning especially on how the environment had influenced learners' affective state and the sources for such anxiety. Early in the 1970s, a distinction has been made between facilitating anxiety and debilitating anxiety. According to Scovel, the former motivates the learner to "fight" the learning task and "gears the learner emotionally for approach behavior", while the latter causes the learner to "flee" and "adopt avoidance behavior" (Scovel, 1978). Following research probed the conditions under which the two types of anxiety would take effect respectively ( for example Andrade $\&$ Williams, 2009; Horwitz, 2012; Liu \& H, 2015). Horwitz (2012) suggests that anxiety becomes facilitating only when the learning task is rather simple, but Andrade and Williams (2009) considers the intensity of the anxiety as the key factor to the distinction. Generally speaking, low anxiety has a facilitating function while high anxiety exerts a debilitating effect due to the distraction of learners' attention and efforts from the task in hand.

As for foreign language writing in particular, lots of research has been done on the relationship between anxiety and achievement on one hand and the sources for such anxiety on the other. The majority of the studies tend to indicate its debilitative effect on learners' emotion and writing achievement (for example Kirmizi \& Kirmizi, 2010; Madden, 
Slavin \& Logan, 2011; Liu, 2014). Madden, Slavin and Logan (2011) believe that foreign language writing is an output process, which involves complex psychological changes and high anxiety will result in negative emotion, lower students' expectation and effort in writing. As for the sources for such writing anxiety, Cheng (2004) ascribes such high anxiety partly to some external factors such as teachers' unpleasant comments, too much concern of others' judgment and uncertainty about their writing capacities.

Polytechnic institutes in China are actually technical training schools for those whose scores in the National Entrance Examination are not high enough for colleges or universities. The average score of the non-English majors in the entrance examination to a polytechnic institute is around 60 out of 120. Some even got lower than 20. In general, the students here are poor in English, lack self-efficacy and have high English writing anxiety (Zhou \& Tang, 2010; Guo \& Qin, 2011; Ji \& Wang, 2012). Ji and Wang conducted a national research on the English learning of polytechnic institute students and their findings have indicated the negative correlation between foreign language writing anxiety and writing achievement. At the same time, instead of general college English writing, which focuses on commentary essays, career English writing such as invitation, resume, order and so on is instructed in polytechnic institutes and such writing pays extra attention to style and organization. Traditional solitary writing mode, in which the assignment is finished independently and handed to the instructor for correction, causes a great deal of fear to the students, which is debilitating to their writing improvement. Therefore, one of the challenges for English teachers is to create a relaxing environment for the learners, in which writing anxiety is alleviated and they feel enthusiastic about writing and experience more positive emotions during the writing process and finally their writing achievement can be improved. Various methods have been suggested to reduce learners' such comprehension, but "most of them were just theoretical hypothesis without much empirical proof" (Zhou \& Tang, 2010).

The unique affective advantages of CL in easing learners' anxiety have been proved theoretically mainly by Social Interdependence Theory, according to which, intrinsic motivation and a joint aspiration are formed in a cooperative group by interpersonal factors and the outcomes of individuals are affected by each other's action (Agarwal \& Nagar, 2011). Numerous studies have also provided empirical support to the facilitating effect of CL (for example Johnson \& Johnson, 2005; Millis, 2010; Storch, 2013; Han, 2014). Early research by Johnson and Johnson reveals that CL has a long-term influence on learners' attitude, affective state and the entire learning atmosphere. A meta-analysis of 122 studies of cooperative learning was done between 1924 and 1981. The findings show that CL is helpful to students in acquiring more knowledge and strategies, improving their psychological health and enhancing their academic achievement (. Other researchers such as Kagan (1994) also suggests the effectiveness of cooperative learning in alleviating anxiety and creating more opportunities for students to produce language. Some Chinese scholars such as Wang Tan, Sheng Qunli and some other scholars have done plenty of study on the theoretical basis, characteristics and effectiveness of CL (for example Wang, 2007; Ning, 2010; Wang, 2013), but CL used in foreign language learning hasn't been given much consideration. This research tried to ease writing anxiety in a foreign language classroom through cooperative learning.

The following research questions were asked:

Can learners' writing anxiety be alleviated significantly through cooperative learning?

If learners' writing anxiety is alleviated effectively, can their writing achievement be improved accordingly?

Further discussion is made on how such changes take place through a series of quantitative and qualitative analysis.

\section{Method}

\subsection{Participants}

The research was carried out in a polytechnic institute of Southern China from July to February in 2013. Participants were freshmen majoring in computer science. Both the experimental group and the comparison group had 60 students. There were altogether 81 females and 39 males in all, ranging from 18 to 20 with a mean age of 19.10 years and had been studying English for 9-12 years with a mean of 11.3 years.

\subsection{Experimental Procedures}

Since collaborative writing was a completely novel experience to the students, steps were taken cautiously so that the participants were fully prepared.

Preparation One month before the experiment, the theory and techniques of cooperative writing were introduced to the participants of the experimental group followed by several small scale pilots. During the month, participants got a chance to know the names, English levels and personalities of each other, preparing for latter group division.

Experiment period The whole experiment was carried out in the first semester. The author was the instructor of 
college English writing class for both the experimental and the comparison group. In the experimental group, participants were divided into groups of four according to their free will. Those groups were heterogeneous to make sure that each group was comprised of members of various English levels, learning styles and personalities. Every group was given a name and one member was selected as the group leader. As suggested by Wang (2013, p. 94-96), mutual learning goals were established in order to make cooperative learning work effectively. To be specific, "shared risks, joint rewards" principle was adopted, i.e. if all the members of one group scored 10 on the writing assignment, each could receive 10 for their performance score, which accounted for $70 \%$ of their final score.

The whole writing procedure consisted of four steps: planning, first drafting, revising and final drafting (Table 1), which is common in the traditional writing, but with a particular "cooperative" nature in this originally designed model. Sharing, explanation, discussion and negotiation were made throughout the whole process and a final mark was given as the group credit instead of an individual score. Four members of the group were responsible for different steps each time, and the total score of the final draft was the group credit, which was also part of the group members' personal score. Seven writing assignments, including meeting notice, customer complaint, memo and so on with the length of about 100 words, were arranged in the experiment. Therefore each member was responsible for any of the four steps at least once. The comparison group was taught in a traditional mode, but the number, topics and length of the writing assignment were the same.

Table 1. Cooperative writing procedure

\begin{tabular}{ll}
\hline Writing steps & Cooperation steps \\
\hline Planning & $\begin{array}{l}\text { Discussion among group members concerning style, content and organization of the } \\
\text { assignment (as shown in Guideline 1). Member 1 takes notes for the ideas. }\end{array}$ \\
$\begin{array}{l}\text { Drafting } \\
\text { Revising }\end{array}$ & $\begin{array}{c}\text { Member } 2 \text { finishes the first draft based on the planning. } \\
\text { in Guideline 2). Member } 3 \text { takes notes on the revised parts. }\end{array}$ \\
Editing & Member 4 finishes the final draft according to the revising opinion and hands it in. \\
\hline
\end{tabular}

Two guidelines were provided to the groups for their planning and editing, which seemed necessary, because the lack of structured guidelines for students to follow, according to some researchers, is one of the main reasons why the practice failed to improve students' writing significantly (Teo, 2007) or many found it frustrating to implement (Dobao, 2012; Storch, 2013). The two guidelines were easier than those in previous studies, but rather practical and convenient to carry out, especially when the time for group discussion in class was so limited. Guideline 1 was for the planning period, including:

1) Share your opinion about the topic in turn, concerning its style, content and organization.

2) Tell each other what you like or dislike about your groupmates' idea and why.

3) Find some confusing parts in your groupmates' idea and ask for clarification.

Considering the unique features of career English writing, style and organization were included in the planning part besides content, while in many other studies, only ideas were emphasized in this step.

Guideline 2 was for the editing period, including:

1) Take turns to tell your what you particularly like about the article.

2) Choose one or two places where you think need improvement.

3) Discuss the confusing parts and ask for clarification.

\subsection{Data Collection Tools}

SLWAI Second Language Writing Anxiety Inventory (SLWAI) (Cheng, 2004) was adjusted and handed out to the participants in the pre-test and the post-test period. The inventory reflected three dimensions of anxiety: cognitive, somatic/physiological and behavioral. A Likert-type scale with five choices was used in scoring. The scale ranged from 1 (strongly agree) to 5 (strongly disagree). All of the positively worded statements, such as "I usually feel comfortable and at ease when writing in English" was reversely scored. Scores from the 27 items were calculated and compared, with the assumption that the higher the score was, the deeper the writing anxiety appeared. Open questions were added in the survey for further exploration.

Achievement tests All the participants took a writing test in both the pre-test and the post-test period. The writing items were taken from College English Level Three Band B, which is a widely used means of assessing English 
achievement of polytechnic students in China. Its reliability and validity are well established. Like most English tests, Band B includes listening, grammar, reading and so on, but has more "career" features. For example, words which are often used at work such as "conference" and "business trip" appear more frequently and the reading and the writing parts are career-centered. The specific writing topic "A Meeting Notice" was taken from the test paper of June, 2011 and the total score was changed to 100 for the convenience of scoring in the research. The same topic was used in the pre-test and the post-test, but considering the long duration of 18 weeks, practice effect can be ignored. The instructor scored the writing according to its organization, language accuracy, length and so on.

Interviews 9 participants, whose foreign language writing anxiety ranked the highest, intermediate and the lowest, were selected to have semi-structured interviews with the instructor during the whole experiment, concerning their attitudes towards cooperative writing and any other changes.

The data collected from the surveys and the tests were analyzed through T-tests in the 18th version of SPSS. The data from the interviews were also transformed into written materials and put into further analysis. Numbers instead of real names were applied to refer to a specific person in the interpretation of the questionnaires and the transcription of the interviews, which insured the students' privacy and encouraged them to express their opinions freely. It was also one of the reasons why the students gave their consent to the research and further interpretation.

\section{Results}

Changes between the two groups and within themselves during the whole process were compared through independent-samples and paired-samples $\mathrm{T}$ tests. $\mathrm{P}$ values $<0.05$ were considered statistically significant.

Research question 1: Can learners' writing anxiety be alleviated significantly through cooperative learning?

To reduce the influence of various factors, independent-samples $T$ tests were conducted both in the experimental group and comparison group in the pre- and post- test period. The result indicates that in the pre-test, the means of scores of foreign language writing anxiety are not significantly different between the experimental group ( mean $=$ $94.78 \pm 9.84)$ and the comparison group (mean $=93.08 \pm 9.64), \mathrm{t}(118)=1.01, \mathrm{p}=0.316$. In the post-test period, when CL had been adopted in the experimental group while traditional teaching mode was conducted in the comparison group, the difference of anxiety between the two groups reached a statistical significance $(\mathrm{p}=$ $0.001<0.05)$.

Table 2. Means and independent-samples T test of English writing anxiety

\begin{tabular}{lllrrrrr}
\hline & Class & $\mathrm{N}$ & Mean & Std.Deviation & \multicolumn{1}{c}{ t } & \multicolumn{1}{c}{ df } & Sig.(2-tailed) \\
\hline Pre-test & Experimental class & 60 & 94.78 & 9.84 & 1.01 & 118 & 0.316 \\
anxiety & Comparison class & 60 & 93.08 & 9.64 & 1.01 & 117.14 & 0.316 \\
\multirow{2}{*}{$\begin{array}{l}\text { Post-test } \\
\text { anxiety }\end{array}$} & Experimental class & 60 & 84.35 & 14.09 & -3.4 & 118 & $0.001^{* *}$ \\
& Comparison class & 60 & 91.97 & 10.18 & -3.4 & 107.39 & $0.001^{* *}$ \\
\hline
\end{tabular}

$* \mathrm{P}<0.05 ; * * \mathrm{P}<0.01$.

As for the changes of participants' writing anxiety within the two groups themselves, Table 3 shows a significant reduction in the experimental group, but not with the comparison group.

Table 3. Paired-samples T test of writing anxiety

\begin{tabular}{|c|c|c|c|c|c|c|c|c|}
\hline & & \multicolumn{4}{|c|}{ Paired Differences } & \multirow[b]{3}{*}{$\mathrm{t}$} & \multirow[b]{3}{*}{ df } & \multirow[b]{3}{*}{ Sig.(2-tailed) } \\
\hline & & \multirow[b]{2}{*}{ Mean } & \multirow[b]{2}{*}{ Std.Deviation } & \multicolumn{2}{|c|}{$\begin{array}{l}\text { 95\% Confidence Interval of the } \\
\text { Difference }\end{array}$} & & & \\
\hline & & & & Lower & Upper & & & \\
\hline Pair 1 & $\begin{array}{l}\text { Experimental class in } \\
\text { pre-test - Experimental } \\
\text { class in post-test }\end{array}$ & 10.43 & 12.47 & 7.21 & 13.65 & 6.48 & 59 & $0.005^{* *}$ \\
\hline Pair 2 & $\begin{array}{l}\text { Comparison class in } \\
\text { pre-test - Comparison } \\
\text { class in post-test }\end{array}$ & 1.12 & 4.98 & 0.17 & 2.40 & 1.74 & 59 & 0.088 \\
\hline
\end{tabular}

Research question 2: If learners' writing anxiety is alleviated effectively, can their writing achievement be improved accordingly? 
In terms of writing achievement, the experimental group $($ mean $=78.08 \pm 9.13)$ and the comparison group $($ mean $=$ $78.18 \pm 8.44)$ is almost at the same level, $\mathrm{t}(118)=-0.06, \mathrm{p}=0.95>0.05$, as shown in Table 4 .

Table 4. Means and independent-samples T test of English writing achievement

\begin{tabular}{llllrrrr}
\hline & Class & $\mathrm{N}$ & Mean & Std.Deviation & \multicolumn{1}{c}{$\mathrm{t}$} & \multicolumn{1}{c}{ df } & Sig.(2-tailed) \\
\hline Pre-test & Experimental class & 60 & 78.08 & 9.13 & -0.06 & 118 & 0.95 \\
achievement & Comparison class & 60 & 78.18 & 8.44 & -0.06 & 117.28 & 0.95 \\
Post-test & Experimental class & 60 & 84.67 & 6.77 & 4.48 & 118 & $0.007^{* *}$ \\
achievement & Comparison class & 60 & 78.57 & 8.09 & 4.48 & 114.46 & $0.007^{* *}$ \\
\hline
\end{tabular}

$$
* \mathrm{P}<0.05 ; * * \mathrm{P}<0.01 \text {. }
$$

However, after the adoption of cooperative writing, the difference reached a statistical significance in the post-test (p $=0.007<0.05)$ as shown in Table 4 .

As for the changes of participants' writing achievement within the two groups themselves, Table 5 clearly illustrates the significant difference in the experimental group $(\mathrm{p}=0.009<0.05)$ and the insignificant difference for the comparison group $(\mathrm{p}=0.324>0.05)$, which proves that cooperative writing approach has increased the participants' writing ability effectively.

Table 5. Paired-samples $\mathrm{T}$ test of writing achievement

\begin{tabular}{|c|c|c|c|c|c|c|c|c|}
\hline & & \multicolumn{4}{|c|}{ Paired Differences } & \multirow[b]{3}{*}{$\mathrm{t}$} & \multirow[b]{3}{*}{ df } & \multirow[b]{3}{*}{ Sig.(2-tailed) } \\
\hline & & \multirow[b]{2}{*}{ Mean } & \multirow[b]{2}{*}{ Std.Deviation } & \multicolumn{2}{|c|}{$\begin{array}{l}\text { 95\% Confidence Interval of } \\
\text { the Difference }\end{array}$} & & & \\
\hline & & & & Lower & Upper & & & \\
\hline Pair 1 & $\begin{array}{l}\text { Experimental class in } \\
\text { pre-test - Experimental } \\
\text { class in post-test }\end{array}$ & -6.58 & 4.52 & -7.75 & -5.42 & -11.28 & 59 & $0.009^{* *}$ \\
\hline Pair 2 & $\begin{array}{l}\text { Comparison class in } \\
\text { pre-test - Comparison } \\
\text { class in post-test }\end{array}$ & -0.38 & 2.99 & -0.16 & 0.38 & -0.99 & 59 & 0.324 \\
\hline
\end{tabular}

\section{Discussion}

\subsection{The Effect of CL on Participants' Writing Anxiety}

The application of cooperative writing resulted in significant reduction of students' writing anxiety $(p=0.005<0.05$, Table 3), which can be rationalized by Social Interdependence Theory. According to the theory, the mutual assistance among group members helps to form positive interpersonal relationship and improve individual psychological health (Agarwal \& Nagar, 2011, p. 32-33). In this case, the alleviation of anxiety can be explained in the following aspects according to the interviews and previous research. Firstly, the "shared risks" principle made them immune of individual humiliation even if the total score was low. The new instruction received warm welcome from the students, which reflected in their meticulous completion of the questionnaires and profound talk in the interviews. One of the most frequently mentioned advantages of cooperative writing was the humiliation-free environment. As one interviewee has stated,

"In the traditional writing mode, I often felt frustrated by low scores and the mistakes located by the teacher. Every time the writings were handed out, I put mine directly into the bag and wouldn't let my classmates see in case my classmates judge me by the scores. The whole writing thing was literally a torture. But now I feel much relieved. Since the credit is given to the whole group, no humiliation is personal and I am free to try what I can. Anyway, my groupmates will give me immediate feedback before the final draft."

From the cited words above and some other interviewees' echoing, it can be inferred that the guarantee of group risk-sharing helped to release learners' writing anxiety when the final draft became the fruit of joint efforts.

Secondly, the atmosphere in the experimental class had changed from being competitive to being supportive and learners' concern of others' judgment could be greatly eased. As one weaker participant put it,

"When writing by myself, lots of uncertainties need to be resolved and I felt helpless. I wouldn't bother my classmates when they cared so much about their own writing. Neither would I turn to the teacher because that would 
catch too much attention and people would think I'm stupid or so eager to succeed. Now we are on the same boat and timely support is always available. Every time I ask for help, I feel proud because I am taking things quite seriously and trying my best to contribute to the whole team."

CL's benefit to low proficient students has been revealed in previous research (for example Andrade \& Williams, 2009; Wang, 2013), but in the Chinese context, high proficient ones also found CL helpful. As one interviewee revealed,

"When writing independently, I found it difficult to be active in class. At the beginning, I shared my ideas a lot, but slackened gradually because the activeness isolated me from my reticent classmates. However, when working in groups, I am regarded as a person with sharp perspectives and have been encouraged a lot by my partners to speak out because it's useful for the improvement of our writing assignment."

The revelation reflects the influence of the Chinese Golden Mean of Confucianism, in which collectivism is accepted as the social norm while eagerness for progress or too much individual performance is not recommended. Such phenomenon had appeared in Ning's research of CL Chinese tertiary learners, who were usually "afraid of being thought of as show-offs" and were likely to "keep silent even if they have some good ideas" (Ning, 2010, p. 67). But in cooperative learning, since all the efforts were made for the benefit of the whole group, high proficient learners were enabled to play to their strengths without being isolated from others. CL, in this case, acted as a platform, justifying weaker students' help seeking and stronger students' tutoring without making anybody feeling embarrassed.

Thirdly, learners' worries about their writing ability could also be effectively reduced and their proficiency got improved during the writing process. The pleasant atmosphere facilitated more opportunities for group members to encourage, praise and support each other. According to the class observations and interviews, learners at different levels did what they could for the common goals and benefit respectively. The intermediate and high proficient participants' writing ability could be improved through speaking out their ideas and clarifying confusing parts. For the low proficient ones, who used to have lots of hesitation in asking for help, CL gave them the trigger to engage themselves more in clearing things up and doing what they could. Otherwise, they couldn't finish their parts of the writing process (as shown in Table 1), making the whole group suffer. Now they managed to contribute brilliant ideas in spite of their low language accuracy. Some even showed their happiness in note taking for their group because they could understand better through writing things down. More importantly, they felt needed when doing something for others. In this way, collectivism's role had changed from being "debilitative" in the traditional independent writing to being "facilitative" in the experimental class, during which CL worked as a turning point by making mutual assistance and individual contribution compulsory.

In fact, with the supportive atmosphere forming in the classroom, the teacher' role was gradually shifting from an authoritative figure to a "facilitator" and a "consulter". One reason was that after deep discussion within their groups, the students turned to the instructor with more specific questions, such as the choices of words in an invitation and even the location of dates in a letter, which made the teachers' suggestions more relevant.

So far, the three main sources for foreign language writing anxiety, i.e. teachers' unpleasant remarks, too much concern of others' judgment and uncertainty about their writing capacities, had been dealt with appropriately in cooperative writing. Of course, not all the debilitating anxiety, which had been accumulated from years of unpleasant writing experiences, could be alleviated by cooperative learning overnight. The degree of the reduction of their writing anxiety varied from person to person in accordance with the intensity of the participants' original worries, their acceptance of cooperative learning and the maturation of its operation. However, it can be assumed that, in general, less debilitating anxiety was endured while more enjoyment of mutual assistance and contribution was conveyed in the experimental class.

\subsection{The Effect of CL on Foreign Language Writing Achievement}

While the significant improvement of the participants' writing ability is probably due to the adoption of cooperative learning and the reduction of writing anxiety, we tend to treat the link carefully given the complexity of the writing process and the distinction between debilitating anxiety and facilitating anxiety. However, the significant reduction of writing anxiety in the experimental class might shed some light on why learners showed more willingness to work harder on their writing assignments and how their writing capacities got improved accordingly. One reason for such improvement is that the writing anxiety in the CL class had been changing from being debilitative to being facilitative as a result of the significant reduction, which has been discussed above. According to Andrade and Williams' principle, the intensity of the anxiety decides the type and a low-anxiety state has a facilitative function 
(Andrade \& Williams, 2009). In this situation, the significant reduction of the writing anxiety in the CL class helped learners restore the hope to "fight" the writing task instead of adopting a negative attitude or just giving up. Such affective changes and its effect to learning can also be theoretically supported by Krashen. The Affective Filter Hypothesis suggests that learners' language input will be "filtered" through their affective factors (Krashen, 1982; Krashen, 2003). As discussed above, the anxiety is greatly relieved in a cooperative writing class, which means the passage of the affective "filter" is widened and language input and writing knowledge can be absorbed better, and therefore learners' writing achievement can be improved significantly.

In the experimental class, one of the most obvious changes was that learners began to take the feedback from their group members and the teacher seriously instead of just putting the suggestions away, which happened in the comparison class. One of the reasons was, as many learners had admitted, that they began to enjoy the writing process and would like to learn more. As one interviewee stated,

"I used to be afraid of the teacher's feedback, because it reminded me how much I need to catch up. What's more, even though I tried to correct the mistakes, new problems would arise in the following assignments. Sometimes I even made the same mistakes, which was rather frustrating. But I am eager to check the feedback with my group members now because we have discussed a lot about the content, grammar and other details and really want to see whether it works. Sometimes, we also argue about the reasonability of the comments and even go to the teacher for further explanation, which is unimaginable compared with my reluctance in the past. Surprisingly, I can remember the knowledge about writing and the language better through all this involvement."

Higher intake of the feedback and lower repetition of the same mistakes have also been mentioned in Storch's book on collaborative writing, in which the author revealed that uptake and retention might be affected by linguistic and affective factors, including the type of errors learners had made in their writing (Storch, 2013, p. 122-123).

Apart from the affective advantages of the CL writing class, attention and cognition reallocation also explains learners' improvement of their writing capacities when the writing anxiety was significantly relieved. As Andrade and Williams have observed, debilitating anxiety diverts a substantial amount of students' attention and caused "inability to concentrate" (Andrade \& Williams, 2009, p. 11). As far as foreign language writing is concerned, the three main sources of learners' writing anxiety have been accumulated from previous unhappy experiences, but have little to do with the writing task in hand. The significant reduction of such task-irrelevant anxieties enabled more attention and cognition to be redirected towards the assignment itself. Learners could put their uncertainties on the table and try to figure out possible ways to deal with them. As one interviewee mentioned,

"...during the discussion about an invitation letter, we spend more time talking about our problems. It is amazing that we have so many uncertainties in common, such as tense and the differences between adjectives and adverbs. If we still could not solve the problems, we would turn to the teacher for help and wouldn't feel ashamed at all. On the contrary, I feel excited because I could actually talk about my problems and got them solved instead of remaining afraid of all sorts of problems or just giving up trying."

The acknowledgement was echoed by several other learners, which proved the affective advantages of cooperative writing and its facilitative effect to language learning, i. e., learners could figure out what their difficulties were when they shared their ideas about a certain topic and asked for clarification through different steps (as shown in Table 1), which resulted in their enhanced achievement.

Furthermore, when learners' anxiety about low-level mistakes such as language accuracy was alleviated, more commitment was put into high-level metacongnitive knowledge and skills. Just as Johnson \& Johnson pointed out, a supportive atmosphere could develop their learning and result in process gain, including higher-level reasoning, more frequent generation of new ideas and so on (Johnson, 1999, p. 72). According to the interviews, through the explanation, clarification and negotiation in the writing steps, more meta-cognitive knowledge on writing such as idea generation as well as language accuracy were acquired or got deeply digested when learners communicated with each other. Intermediate and high proficient participants' writing ability could also be improved through speaking out their ideas and clarifying the confusing parts.

With better performance in their writing, learners felt less anxiety and more confidence. Meanwhile, with lower anxiety, their writing achievement would get enhanced further. Thus, a benign circle was formed between learners' writing anxiety and their writing achievement.

One thing worth discussing is the decreasing of writing achievement of the comparison group. It might seem impossible that the learners' writing ability didn't improve after a whole semester's study, but it is actually quite common in many polytechnic institutes even colleges that learners' English level wouldn't improve at all if their 
English learning is not effective. That's why learners in those schools are encouraged to take College English Level Three Band B test in the early session of the first semester when their English is still fine after the intense training for the National Entrance Examination.

\subsection{Some Advice for Teachers}

Some pedagogical experience has been acquired from the study and may be helpful for all stakeholders in ELT locally and internationally.

Elaborate preparation. A preparation period around one month is necessary and various activities can be arranged to provide learners with enough chances to get to know their classmates' language levels, learning styles, personalities and so on so that they can make a discrete choice on their group members.

Group forming. Previous research has emphasized the heterogeneity of CL groups (for example Johnson, 2009; Storch, 2013). However, more local elements should be taken into consideration. For example, some learners chose to stay with their friends or roommates due to Chinese or even Asian people's concept of interpersonal harmony, but according to the interviews, they preferred to work with high proficient ones deep down inside. So it's crucial for the teacher to sense the need and coordinate group forming carefully without causing any embarrassment.

Teachers' role. The teacher's participation in cooperative writing should be withdrawn gradually. For the students in China and other Asian countries, the teacher stands for the authority and they won't feel safe or satisfied until the teacher reads through their writings sentence by sentence and makes thorough comments. To make them believe that cooperative writing is a formal and useful instruction, the teacher need to set sufficiently detailed guidelines for each step of the writing process and even check with the group members together to make their group discussion effective and efficient.

\section{Conclusion}

This study contributes to the implementation of cooperative learning in the writing class of a polytechnic institute, proving it to be a feasible and effective approach to alleviate learners' writing anxiety significantly and increase their writing competence greatly. When generalizing the findings of the present study, however, one should use caution because many things can influence learners' writing anxiety, such as their motives, learning styles and language proficiency, but only the instruction of cooperative learning was considered as the main factor that differed the experimental group and the comparison group. Therefore, additional research should testify how effective CL is when those factors are also taken into account.

Studies on cooperative writing are in great lack or in Storch's words "in its infancy" (Storch, 2013, p. 193), so there's still a lot of room for improvement. Further research can be done on the varieties of cooperative writing, such as encouraging inter-team competition to heighten team-spirit or incorporating improvement points to indicate teams' improvements over their previous work. More studies can also be done on how cooperative learning will take effect when used in English listening, speaking and reading, so that a comprehensive view can be obtained on the application of $\mathrm{CL}$ in foreign language learning and teaching.

\section{Acknowledgements}

This research was supported by Grant No.20, 2007 from the China Department of Higher Education and Grant No. 2, 2015 "The Model Building of Foreign English Teachers' Professional Development in Polytechnic Institutes" from English Teaching Guide Committee of Higher Vocational Education in Guangdong Province. Lots of thanks should be given to Hongjun Li, Xuelin Qiu and Liqing Liang for their proof reading and all the support.

\section{References}

Agarwal, R., \& Nagar. N. (2011). Cooperative Learning. Delhi: Kalpaz Publications.

Andrade, M., \& Williams. K. (2009). Foreign language learning anxiety in Japanese EFL university classes: Physical, emotional, expressive and verbal reactions. Sophia Junior College Faculty Journal, 29, 1-24.

Cheng, Y. (2004). A measure of second language writing anxiety: Scale development and preliminary validation. Journal of Second Language Writing, 13 (4), 13-335. http://dx.doi.org/10.1016/j.jslw.2004.07.001

Dobao, A. F. (2012). Collaborative writing tasks in the L2 classroom: Comparing group, pair and individual work. Journal of Second Language Writing, 21, 40-58. http://dx.doi.org/10.1016/j.jslw.2011.12.002

Davidson, N., \& Major, C. H. (2014). Boundary crossings: Cooperative learning, collaborative learning, and problem-based learning. Journal on Excellence in College Teaching, 25, 7-55. 
Guo, Y., \& Qin. X. (2011). English writing anxiety report and implications to writing teaching. Foreign Language World, 33 (2), 64-68.

Horwitz, E. K., Horwitz, M. B., \& Cope. J. A. (1986). Foreign Language Classroom Anxiety. The Modern Language Journal, 70 (2), 125-132. http://dx.doi.org/10.1111/j.1540-4781.1986.tb05256.x

Horwitz, E. K. (2012). Becoming a Language Teacher: A Practical Guide to Second Language Learning and Teaching. Boston: Allyn \& Bacon.

Ji, S. and Wang. Z. (2012). Theoretical and Practical Exploration on Higher Vocational English Education. Beijing: Beijing Normal University Publishing Group.

Johnson, W. D., \& Johnson. T. R. (1999). Making cooperative learning work. Theory into Practice, 38 (2), 67-73. http://dx.doi.org/10.1080/00405849909543834

Johnson, W. D., \& Johnson. T. R. (2005). New development in social interdependence theory. Genetic, Social, and General Psychological Monograph, 131 (4), 285-358. http://dx.doi.org/10.3200/MONO.131.4.285-358

Johnson, W. D., \& Johnson. T. R. (2009). An educational psychology success story: Social interdependence theory and cooperative learning. Educational Researcher, 38 (5), 365-379. http://dx.doi.org/10.3102/0013189X09339057

Kagan, S. (1994). Cooperative Learning. San Clemente: Kagan Publishing .

Kirmizi, O., \& Kirmizi. G. D. (2015). An investigation of L2 Learners' Writing Self-efficacy, writing anxiety and its causes at Higher Education in Turkey. International Journal of Higher Education, 4 (2), 57-66. http://dx.doi.org/10.5430/ijhe.v4n2p57

Krashen, D. S. (1982). Acquiring a second language. World Englishes, 1 (3), 97-101. http://dx.doi.org/10.1111/j.1467-971X.1982.tb00476.x

Krashen, D. S. (2003). Explorations in Language Acquisition and Use: The Taipei lectures. Portsmouth, NH: Heinemann.

Han, H. (2014). Transforming EFL Classes from Lecturing to Cooperative Learning. Journal of Language Teaching and Research, 5, 948-952. http://dx.doi.org/10.4304/jltr.5.4.948-952

Liu, D. (2014). Research on the Psychology and Language of ESL Writing. Beijing: China University of Geosciences Press.

Liu, M., \& H. N. (2015). Chinese University EFL Learners' Foreign Language Writing Anxiety: Pattern, Effect and Causes. English Language Teaching, 8, 46-58. http://dx.doi.org/10.5539/elt.v8n3p46

Madden, N. A., Slavin. R. E., \& Logan. M. (2011). Effects of cooperative writing with embedded multimedia: a randomized experiment. Effective Education, 3 (1), 1-9. http://dx.doi.org/10.1080/19415532.2011.603914.

Millis, B. (2010). Cooperative Learning in Higher Education: Across the Disciplines, across the Academy. Sterling VA: Stylus Publishing LLC .

Ning, H. (2010). Adapting cooperative learning with teritary ELT. ELT Journal, 65 (1), 60-70. http://dx.doi.org/10.1093/elt/ccq021

Scovel, T. (1978). The effect of affect: A review of the anxiety literature. Language Learning, 28 (1), 129-142. http://dx.doi.org/10.1111/j.1467-1770.1978.tb00309.x

Storch, N. (2013). Collaborative Writing in L2 Classrooms. Bristol: Multilingual Matters Limited.

Teo, A. S. (2007). A writing method to help English language learners. English Teaching Forum, 4, 18-25.

Wang, T. (2007). Wang Tan. An introduction to cooperative instruction. Jinan, China: Shandong Education Press.

Wang, T. (2013). Basic Principles of Cooperative Instruction. Jinan, China: Shandong Education Press.

Wyeld, T. G. (2013). Using activity theory to study cooperative learning. Int. J. Innovation and Learning, 13, 430-450. http://dx.doi.org/10.1504/IJIL.2013.054238

Zhou, B., \& Tang. J. (2010). An empirical study of the influence of L2 writing apprehension on L2 writing process. Foreign Language Education, 31 (1), 64-68. 


\section{Appendix:}

Second Language Writing Anxiety Inventory (SLWAI) adapted from Cheng, Y. S. (2004)

This questionnaire has been arranged to observe how you feel about writing in English as a second language. Read each statement carefully and rate your feelings about ESL writing. Please consider that the information is confidential and will be used just for analyzing the data for this research. Use the scale below to answer the questions.

\section{I strongly agree $(\mathrm{SA})$ \\ 2. I agree (A) \\ 3. I have no strong feelings either way $(\mathrm{N})$ \\ 4. I disagree (D) \\ 5. I strongly disagree (SD)}

1. While writing in English, I am not nervous at all.

2. I feel my heart pounding when I write English compositions under time constraint..

3. While writing English compositions, I feel worried and uneasy if I know they will be evaluated.

4. I often choose to write down my thoughts in English.

5. I usually do my best to avoid writing English compositions.

6. My mind often goes blank when I start to work on an English composition.

7. I don't worry that my English compositions are a lot worse than others.

8. I tremble or perspire when I write English compositions under time pressure.

9. If my English composition is to be evaluated, I would worry about getting a very poor grade.

10. I do my best to avoid situations in which I have to write in English.

11. My thoughts become jumbled up when I write English compositions under time constraint.

12. Unless I have no choice, I would not use English to write compositions.

13. I often feel panic when I write English compositions under time constraint.

14. I am afraid that the other students would deride my English composition if they read it.

15. I freeze up when unexpectedly asked to write English compositions.

16. I would do my best to excuse myself if asked to write English compositions.

17. I don't worry at all about what other people would think of my English compositions.

18. I usually seek every possible chance to write English compositions outside of class.

19. I usually feel my whole body rigid and tense when write English compositions.

20. I am afraid of my English composition being chosen as a sample for discussion in class.

21. I am not afraid at all that my English compositions would be rated as very poor.

22. Whenever possible, I would use English to write compositions.

23. While writing in English, I often worry that the ways I express and organize my ideas do not conform to the norm of English writing.

24. While writing in English, I often worry that I would use expressions and sentence patterns improperly.

25. I usually feel comfortable and at ease when writing in English.

26. When I write in English, my ideas and words usually flow smoothly.

27. When I write in English, my mind is usually very clear.

Open questions:

1. How do you like the present writing? Please specify.

2. What changes would you like to see in the future writing class? 